Western North American Naturalist 68(2), (C) 2008, pp. 245-248

\title{
CAPTURE RATES OF REPTILES AND AMPHIBIANS ON BLACK-TAILED PRAIRIE DOG (CYNOMYS LUDOVICIANUS) COLONIES AND ON UNCOLONIZED PRAIRIE IN COLORADO
}

\author{
Bryon K. Shipley ${ }^{1,2}$, Richard P. Reading ${ }^{1}$, and Brian J. Miller ${ }^{3}$
}

\begin{abstract}
Prairie dog eradication negatively affects dependent wildlife. Assessing the effects of prairie dog activities on reptiles and amphibians may depend upon the efficacy of trapping designs. We compared capture rates of reptiles and amphibians on black-tailed prairie dog (Cynomys ludovicianus) colonies and on adjacent uncolonized short-grass prairie, using funnel traps and pitfall traps with drift fences, as well as ground captures. We captured 152 reptiles and amphibians representing 10 species. We captured $51.3 \%$ of all reptiles and amphibians on colonies, compared to $48.7 \%$ from uncolonized sites. Overall, captures of reptiles and amphibians were similar on colonies and uncolonized sites for all capture methods combined. We achieved higher capture rates on uncolonized sites using funnel traps and pitfall traps but higher capture rates on colonies for ground captures. For all years on all sites combined, we captured significantly more animals in funnel traps (52.6\%), surpassing pitfall trap captures $(23.0 \%)$ and ground captures $(24.3 \%)$. We recommend using multiple $Y$-shaped drift fence arrays $\geq 7.6 \mathrm{~m}$ in length, funnel traps with double-ended openings, and black-colored pitfall traps with opening diameters $\geq 30 \mathrm{~cm}$.
\end{abstract}

Key words: Cynomys ludovicianus, reptiles, amphibians, capture rates, prairie.

Black-tailed prairie dog populations throughout North America have declined by over $98 \%$ since the turn of the century (Marsh 1984). Eradication of prairie dog colonies has had a negative effect on many animals dependent on these colonies, although studies of reptiles, amphibians, and prairie dogs (Kretzer and Cully 2001, Lomolino and Smith 2003, Shipley and Reading 2006) have demonstrated that populations of reptiles and amphibians can be negatively and positively affected by prairie dogs. Assessment of the effects of prairie dog activities on reptiles and amphibians may depend upon the efficacy of trapping designs. Because few studies have addressed the effectiveness of reptile and amphibian capture methods in short-grass prairie, we used funnel traps, pitfall traps, and ground captures to compare capture rates of reptiles and amphibians on black-tailed prairie dog (Cynomys ludovicianus) colonies and on adjacent uncolonized short-grass prairie.

We conducted the study at the Plains Conservation Center (PCC) in Arapahoe County, Colorado $\left(39^{\circ} 39^{\prime} \mathrm{N}, 104^{\circ} 44^{\prime} \mathrm{W}\right)$, during MaySeptember from 2001 to 2003. The PCC consists of 445 ha of short-grass prairie, spanning an elevation range of 1728-1783 m. We selected
3 prairie dog colonies and matched them to uncolonized sites (2 in 2001 and 3 in 20022003) within the PCC. A portion of 1 of the uncolonized sites in 2002 was colonized by prairie dogs, so data from this site were excluded from analysis. Uncolonized sites were established at distances of 582-878 m from colonies and selected based on topographic and vegetative similarities to their corresponding study colonies.

Within each colony and uncolonized site, we constructed 2 drift fence arrays (Jones 1986) at randomly selected locations, incorporating pitfall and funnel traps (modified from Fitch 1987) into an array design following Shipley and Reading (2006). We employed 40 pitfall traps (24 on colonies and 16 on uncolonized sites) and 30 funnel traps (18 on colonies and 12 on uncolonized sites) in 2001. In 20022003, we used 48 pitfall traps (24 on colonies and 24 on uncolonized sites) and 72 funnel traps (36 on colonies and 36 on uncolonized sites). While checking traps, we conducted visual surveys for reptiles and amphibians on the ground. We performed the surveys at the same time each morning, with 2 people entering and exiting each site from the same access point. Areas between arrays on each site were

\footnotetext{
${ }^{1}$ Denver Zoo, 2300 Steele Street, Denver, CO 80205.

2E-mail: bshipley@denverzoo.org

${ }^{3}$ Wind River Foundation, Watrous, NM 87753.
} 
TABLE 1. Reptile and amphibian species captured using different trapping methods on black-tailed prairie dog (Cynomys ludovicianus) colonies and on uncolonized sites in Colorado, 2001-2003. FNL = funnel trap, PF = pitfall trap, GR $=$ ground capture.

\begin{tabular}{|c|c|c|c|c|c|c|c|c|c|c|c|c|}
\hline \multirow[b]{2}{*}{ Species } & \multicolumn{4}{|c|}{ All sites combined } & \multicolumn{4}{|c|}{ On colonies } & \multicolumn{4}{|c|}{ Uncolonized sites } \\
\hline & FNL & $\mathrm{PF}$ & GR & All & FNL & $\mathrm{PF}$ & GR & All & FNL & $\mathrm{PF}$ & GR & All \\
\hline Thamnophis radix & 8 & 2 & 0 & 10 & 4 & 1 & 0 & 5 & 4 & 1 & 0 & 5 \\
\hline Thamnophis elegans & 4 & 0 & 2 & 6 & 1 & 0 & 2 & 3 & 3 & 0 & 0 & 3 \\
\hline Crotalus viridis & 22 & 2 & 17 & 41 & 12 & 1 & 15 & 28 & 10 & 1 & 2 & 13 \\
\hline Pituophis catenifer & 29 & 0 & 4 & 33 & 11 & 0 & 2 & 13 & 18 & 0 & 2 & 20 \\
\hline Tropidoclonion lineatum & 1 & 0 & 1 & 2 & 0 & 0 & 0 & 0 & 1 & 0 & 1 & 2 \\
\hline Phrynosoma hernandesi & 1 & 3 & 9 & 13 & 1 & 3 & 9 & 13 & 0 & 0 & 0 & 0 \\
\hline Eumeces multivirgata & 0 & 5 & 2 & 7 & 0 & 2 & 1 & 3 & 0 & 3 & 1 & 4 \\
\hline Ambystoma tigrinum & 8 & 10 & 1 & 19 & 3 & 1 & 1 & 5 & 5 & 9 & 0 & 14 \\
\hline Scaphiopus bombifrons & 7 & 9 & 0 & 16 & 4 & 1 & 0 & 5 & 3 & 8 & 0 & 11 \\
\hline Pseudacris triseriata & 0 & 4 & 1 & 5 & 0 & 2 & 1 & 3 & 0 & 3 & 0 & 2 \\
\hline TOTAL & 80 & 35 & 37 & 152 & 36 & 11 & 31 & 78 & 71 & 32 & 7 & 74 \\
\hline
\end{tabular}

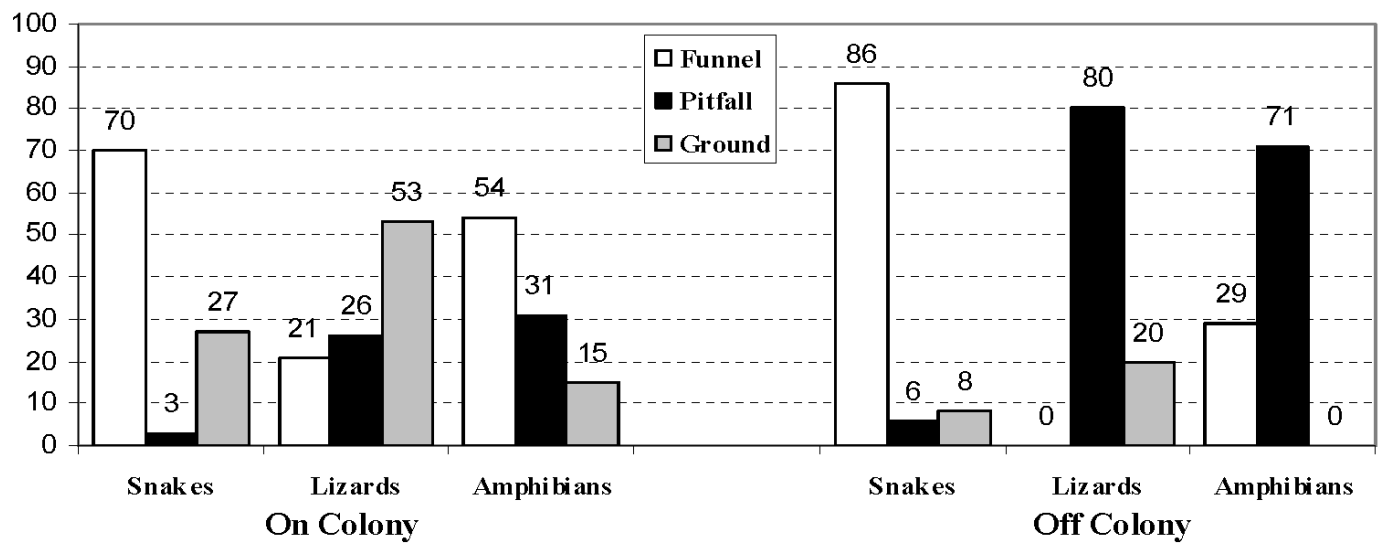

Fig. 1. Percent of total reptiles and amphibians captured using different trap methods on black-tailed prairie dog (Cynomys ludovicianus) colonies and on uncolonized sites in Colorado.

included. On any particular day, the same people performed all surveys, although availability of specific volunteers on a given day was subject to change. Maximum sight radius on either side of the walking line was limited to approximately $5.5 \mathrm{~m}$.

Beginning in mid-May of each year, we opened traps for 7-10 days twice a month, checking traps daily, until mid-September. We compared capture rates between methods (i.e., funnel traps, pitfall traps, and ground captures) using the Pearson chi-square test for goodness-of-fit. We compared colony sites and uncolonized sites using the Pearson chi-square test with a Yate's correction.

During the 2001-2003 study (Shipley and Reading 2006), we captured 152 reptiles and amphibians, representing 10 species (Table 1). We captured $51.3 \%(n=78)$ of all reptiles and amphibians on colonies, compared to $48.7 \%$ ( $n$ $=74$ ) on uncolonized sites. We pooled capture data from 2001 through 2003 for the analyses of capture rates. Overall, captures of reptiles and amphibians were similar on colonies and on uncolonized sites for all capture methods combined (Yate's $\chi^{2}=2.10$, df $=1, P=0.15)$. We achieved higher capture rates on uncolonized sites using funnel traps (Yate's $\chi^{2}=5.20, \mathrm{df}=1, P=0.02$ ) and pitfall traps (Yate's $\chi^{2}=9.26, \mathrm{df}=1, P<0.01$ ), but higher capture rates on colonies for ground captures (Yate's $\chi^{2}=8.94, \mathrm{df}=1, P<0.01$ ).

For all years on all sites combined, we captured significantly more animals $\left(\chi^{2}=61.76\right.$, $\mathrm{df}=2, P<0.001)$ in funnel traps $(52.6 \%, n=$ 80), surpassing pitfall trap captures $(23.0 \%, n$ $=35)$ and ground captures $(24.3 \%, n=37$; Fig. 1). Captures of lizards on colonies were 
limited to ground captures of short-horned lizards (Phrynosoma hernandesi) on 1 colony only (see also Fair and Henke 1997) and 2 many-lined skinks (Eumeces multivirgata), 1 on each of 2 other colonies. Phrynosoma hernandesi was not found on uncolonized sites. Lizard captures on uncolonized sites consisted entirely of Eumeces multivirgata, primarily from pitfalls, followed by ground captures, while none were from funnel traps.

Amphibians were captured on colonies by all methods, primarily by funnel traps and secondarily by pitfalls, while ground captures were limited to 1 each of tiger salamander (Ambystoma tigrinum) and western chorus frog (Pseudacris triseriata). On uncolonized sites, amphibians were captured primarily by pitfalls and secondarily by funnel traps. We made no ground captures of amphibians on uncolonized sites.

Prairie dog activities on colonies may have contributed to variations in our trapping results. Reduced vegetation on colonies, a condition created by prairie dog activity (Whicker and Detling 1988, Winter et al. 2002), likely enhanced both the visual detection of reptiles and amphibians and the probability of capture compared to uncolonized sites. Significantly higher snake captures on colonies, compared to uncolonized sites $\left(\chi^{2}=6.84\right.$, $\left.\mathrm{df}=1, P<0.01\right)$, were due at least in part to larger numbers of prairie rattlesnake (Crotalus viridis), which were present seasonally and easily observed in the shorter vegetation. Fewer large snakes (3\%), such as Crotalus viridis and bullsnakes (Pituophis catenifer), were trapped in pitfalls than small snakes $(11 \%)$, such as the plains garter snake (Thamnophis radix), western terrestrial garter snake (Thamnophis elegans), and lined snake (Tropidoclonion lineatum). A higher capture rate of small snakes than of large snakes in pitfall traps suggests that larger snakes can escape from, or avoid falling into, pitfall traps; however, the few pitfall captures of both large and small snakes precluded statistical analyses. We captured only 2 specimens of the fossorial snake Tropidoclonion lineatum, both on uncolonized sites in a funnel trap and via ground capture. These small snakes seem to avoid pitfalls, perhaps because of their secretive behavior and small home ranges, which reduce encounters with pitfalls (Crosswhite et al. 1999).

Comparatively few studies report on reptile and amphibian trapping efficacy in grassland habitat. In Kansas short-grass prairie, Kretzer and Cully (2001) used Y-shaped drift fences with funnel traps and pitfalls but did not report capture rates. In spinifex grasslands of Australia, Morton et al. (1988) found that drift fences increased capture rates. Specifically, drift fences with crossing arms were more effective than those with single arms, and pitfalls of larger diameter captured more animals than pitfalls of smaller diameter. In semiarid grasslands of South Africa, Douglas (1995) reported that funnel traps caught $68 \%$ of reptiles and amphibians when used with drift fences, compared to pitfalls alone. In mixed mesquite shrubland-prairie grassland, Fair and Henke (1997) captured Phrynosoma cornutum almost equally with pitfalls and funnel traps used with Y-shaped drift fences, although systematic visual searching proved more effective. We found similar results for Phrynosoma hernandesi. Christiansen and Vanderwalle (2000) found that turtles in relict sand prairie were more apt to be caught in funneled wire box traps (Iverson 1991) and flip-top pitfalls used with single-line drift fences, whereas open-top pitfalls more effectively captured amphibians, lizards, and small mammals.

Our results indicate that trapping success can vary significantly between sites on prairie dog colonies and sites on uncolonized grassland. Susceptibility of reptiles and amphibians to trapping may be affected by numerous biological factors (Bury and Corn 1987, Fitch 1992, Douglas 1995, Fair and Henke 1997, Enge 1998, Jorgensen et al. 1998, Crosswhite et. al. 1999, Jenkins et al. 2003, Shipley and Reading 2006) and species' behavioral responses (Enge and Wood 1998). Trapping design may also influence species' catchability (Morton et al. 1988, Greenberg et al. 1994, Enge 1997, 1998, 2001, Fair and Henke 1997, Webb 1999). To maximize trapping efficiency on prairie dog colonies and adjacent grassland, we recommend using multiple $\mathrm{Y}$-shaped drift fence arrays with lengths $\geq 7.6 \mathrm{~m}$, funnel traps with double-ended openings (Greenberg et al. 1994, Crosswhite et al. 1999), and black-colored pitfall traps (not used in our study; Crawford and Kurta 2000) with opening diameters $\geq 30 \mathrm{~cm}$ (Morton et al. 1988, Thompson et al. 2005).

The Plains Conservation Center staff, under Executive Director Tudi Arneill and Director 
of Education Fran Blanchard, graciously supported this study. Financial support was provided by the Denver Zoo's Department of Conservation Biology. A scientific collection permit was provided by the Colorado Division of Wildlife. Applicable institutional guidelines for animal care were followed. Rick Haeffner and Charles Radcliffe provided logistic support. Many thanks go to Jake Dewey, Hani Freeman, Chuck and Betty Mulcahy, Katrina Rewerts, Traci Schillinger, Leighton Thompson, and Mary Wisz for helping to check traps and collect data. We thank the following people for their support and ideas: Jeff Baiers, Steven Beaupre, Matt Goode, Andy Holycross, and Steve MacKessy. Special thanks go to Scott Qualls, who engineered our funnel trap design.

\section{Literature Cited}

BurY, R.B., AND P.S. CoRn. 1987. Evaluation of pitfall trapping in northwestern forests: trap arrays with drift fences. Journal of Wildlife Management 51: 112-119.

Christiansen, J.L., and T. Vandewalle. 2000. Effectiveness of three trap types in drift fence surveys. Herpetological Review 31:158-160.

Crawford, E., AND A. Kurta. 2000. Color of pitfall affects trapping success for anurans and shrews. Herpetological Review 31:222-223.

Crosswhite, D.L., S.F. Fox, And R.E. Thill. 1999. Comparison of methods for monitoring reptiles and amphibians in upland forests of the Ouachita Mountains. Proceedings of the Oklahoma Academy of Science 79:45-50.

Douglas, R.M. 1995. The herpetofauna of Florisbad Research Station as largely determined by array trapping. Navorsinge Van Die Nasionale Museum Bloemfontein 11(Part 6):121-148.

Enge, K.M. 1997. Use of silt fencing and funnel traps for drift fences. Herpetological Review 28:30-31. 1998. Herpetofaunal drift fence survey of an upland hardwood forest, Gadsen County, Florida. Final Performance Report, Florida Game and Freshwater Fish Commission, Tallahasee, Florida. ii +26 pp. . 2001. The pitfalls of pitfall traps. Journal of Herpetology 35:467-478.

Enge, K.M., AND K.N. Wood. 1998. Herpetofaunal surveys of the Big Bend Wildlife Management Area, Taylor County, Florida. Florida Scientist 61:62-87.

FAIR, W.S., AND S.E. HENKE. 1997. Efficacy of capture methods for a low density population of Phrynosoma cornutum. Herpetological Review 28:135-137.

Fitch, H.S. 1987. Collecting and life-history techniques. Pages 150-151 in R.A. Seigel, J.T. Collins, and S.S. Novak, editors, Snakes: ecology and evolutionary biology. McGraw-Hill Publishing Co., New York.

. 1992. Methods of sampling snake populations and their relative success. Herpetological Review 23:1718.
Greenberg, C.H., D.G. Neary, and L.D. Harris. 1994. A comparison of herpetofaunal sampling effectiveness of pitfall, single-ended, and double-ended funnel traps used with drift fences. Journal of Herpetology 28:319-324.

Iverson, J.B. 1991. Life history and demography of the yellow mud turtle, Kinosternum flavescens. Herpetologica 47:373-395.

Jenkins, C.L., K. McGarigal, and L.R. Gamble. 2003. Comparative effectiveness of two trapping techniques for surveying the abundance and diversity of reptiles and amphibians along drift fence arrays. Herpetological Review 34:39-42.

JonEs, K.B. 1986. Amphibians and reptiles. Pages 267290 in A.Y. Cooper, R.J. Boyd, and H.R. Stuart, editors, Inventory and monitoring of wildlife habitat. U.S. Department of the Interior, Bureau of Land Management, Service Center, Denver, CO.

Jorgensen, E.E., M. Vogel, and S. Demarais. 1998. A comparison of trap effectiveness for reptile sampling. Texas Journal of Science 50:235-242.

Kretzer, J.E., AND J.F. Cully, Jr. 2001. Effects of blacktailed prairie dogs on reptiles and amphibians in Kansas short-grass prairie. Southwestern Naturalist 46:171-177.

Lomolino, M.V., AND G.A. SMith. 2003. Terrestrial vertebrate communities at black-tailed prairie dog (Cynomys ludovicianus) towns. Biological Conservation 115:89-100.

Marsh, R.E. 1984. Ground squirrels, prairie dogs, and marmots as pests on rangeland. Pages 195-208 in Proceedings of the Conference for Organization and Practise of Vertebrate Pest Control, August 30-September 3, 1982, Hampshire, England. ICI Plant Protection Division, Fernherst, England.

Morton, S.R., M.W. Gilliam, K.R. Jones, and M.R. FLEMING. 1988. Relative efficiency of different pittrap systems for sampling reptiles in spinifex grasslands. Australian Wildlife Research 15:571-577.

Shipley, B., AND R. REading. 2006. A comparison of herpetofauna and small mammal diversity on blacktailed prairie dog (Cynomys ludovicianus) colonies and non-colonized grasslands in Colorado. Journal of Arid Environments 66:27-41.

Thompson, S.A., G.G. Thompson, and P.C. Withers. 2005. Influence of pit trap type on the interpretation of fauna diversity. Wildlife Research 32:131-137.

Webв, G.A. 1999. Effectiveness of pitfall/drift fence systems for sampling ground-dwelling lizards and frogs in southeastern Australian forests. Australian Zoologist 31:118-126.

Whicker, A.D., AND J.K. Detling. 1988. Ecological consequences of prairie dog disturbances. BioScience 38:778-785.

Winter, S.L., J.F. CulLy, And J.S. Pontius. 2002. Vegetation of prairie dog colonies and non-colonized shortgrass prairie. Journal of Range Management 55:502508.

Received 2 January 2007
Accepted 24 January 2008 